\title{
Hydrodynamics and Heat Transfer to Vertically Flowing Gas-Solids Suspensions $\dagger$
}

\author{
Yuri Molodtsof* \\ Département de Génie Chimique \\ Université de Technologie de Compiegne
}

\begin{abstract}
Vertically flowing gas-solids suspensions have been investigated both theoretically and experimentally. The theoretical approach suggested the possibility of self-similar flow patterns for the particles at low solids concentration. The experiments carried out on two different installations with four different solids confirmed the existence of a so - called similar profiles regime bounded at dilute-phase flow conditions. At a constant gas velocity, a sudden transition occurs for a critical solids concentration. Beyond this limit particle concentration increases faster with increasing solids rate. These similarity properties have been eventually extended to the temperature profiles, which allowed the derivation of a general wall-to-suspension heat transfer equation containing two shape factors summarizing the flow hydrodynamics. This equation proved to be in excellent agreement with experimental results. Moreover, beyond the flow regime transition, i.e. in dense-phase flow, the same equation applies with modified shape factors.
\end{abstract}

\section{Introduction}

Gas-solids suspensions flow vertically in many industrial processes, ranging from pneumatic transport to fluidized bed reactors, including risers in the petroleum industry, transport reactors and circulating fluidized beds. Consequently, a considerable amount of work has been devoted to the problem. Muzyka ${ }^{15}$, recently presented a comprehensive review of these earlier works concerned with either hydrodynamics or heat transfer. The first generation of papers was mainly concerned with pneumatic transport and, therefore, directed toward the prediction of overall pressure drop and average slip between the phases. In this connection, Hariu and Molstad ${ }^{4)}$, suggested considering the overall pressure drop under fully developed flow conditions as the sum of three contributions: gas friction, gravity, and wallparticle interaction. Moreover, they suggested accounting for the latter using a particle friction factor. The concept was widely used for a while but failed in predicting a curious experimental observation: the so-called negative

* B.P. 649, F - 60206 Compiègne, FRANCE

$\dagger$ Recieved June 10, 1992 drag $^{15)}$ which occurs under certain operating conditions.

In the 1960 s, gas-solids suspensions were considered as possible coolant media for nuclear reactors. During this period, theoretical attempts as well as experimental studies were aimed at predicting the variation of the wall-to -suspension heat transfer coefficient with solids loading. Empirical approaches resulted in a number of correlations predicting contradictory trends of variation as shown, e.g., by Maeda et a1. ${ }^{5}$. Moreover, theoretical attempts failed in explaining these discrepancies. With the development of circulating fluidized bed reactors, a renewed interest appeared in the literature for heat transfer, especially in connection with applications to coal combustion reactors from which great amounts of heat should be removed. Besides this, as far as modelling for the prediction of reaction efficiency became an actual concern, numerous papers have been published on the distribution of the phases throughout the riser. Those dealing with the radial profiles of either particle concentration or both-phases velocites have been reviewed in a recent paper ${ }^{11}$. 
the results discussed hereafter are mainly those obtained as part of a long-term program of the Suspensions and Powder Technology Group of the Compiègne University of Technology. One part of this program was operated in collaboration with the University of Western Ontario (Canada). The research program concerned the investigation of the overall and local characteristics of the hydrodynamics of vertically flowing gas-solids suspensions. In addition, particular attention was paid to the wallto-suspension heat transfer problem. Experimental investigations were carried out on two different installations with their specific characteristics and measuring facilities. They were intimately combined with a general and rigorous theoretical approach in order to obtain general properties of vertical gas-solids flow.

\section{Theoretical Approach}

\subsection{General Equations}

A general theoretical framework allowing a rigorous mathematical description of multiphase mixtures, termed probabilistic Eulerian description, has been developed ${ }^{9,10}$. According to this approach, the presence and all physical quantities (i.e. immediate Eulerian variables) of each phase are random variables governed by laws of probability determined by the overall boundary conditions imposed to the flow. A given phase $\mathrm{p}$ in the mixture is then characterized by a phase presence probability $\alpha_{\mathrm{p}}$ and probabilistic mean Eulerian variables of the phases are defined as the expected value of the random immediate Eulerian variable under consideration. The general probabilistic multiphase flow equations are written in terms of these "phase mean variables" which are shown" to be identifiable with measurable quantities in the flow.

The probabilistic approach to general equations is well adapted to the analysis of the flow structure since these are local equations written in terms of local variables defined so as not to be dependent on the existence of an appropriate spatial or temporal averaging domain. Besides, among rigorously derived general flow equations, they are the only ones to account for the specifics of gas-solids suspensions, particularly addressing the interactions between particles ${ }^{15}$. In the analysis below, all particle phases are treated as the overall "solids" phase. The conditions under which this is valid (i.e. when all the particles have the same physical properties such as density, regardless of their size or shape) were studied by Molodtsof and Muzyka ${ }^{10)}$.

For any phase $\mathrm{p}$ in the mixture, a continuity equation is derived:

$\frac{\partial}{\partial t}\left(\rho_{p} \alpha_{p}\right)+\frac{\partial}{\partial x_{j}}\left(\rho_{p} \alpha_{p} V_{j}^{p}\right)=0$

where $\rho_{\mathrm{p}}$ denotes the phase p density and $\mathrm{V}_{\mathrm{j}}^{\mathrm{p}}$ are the components of the phase mean velocity. The momentum equation of the overall "solids" phase, when projected on the $\mathrm{Ox}_{\mathrm{i}}$ axis, takes the following form

$$
\begin{aligned}
& \frac{\partial}{\partial t}\left(\rho_{\mathrm{s}} \alpha_{\mathrm{s}} V_{\mathrm{i}}\right)+\frac{\partial}{\partial \mathrm{x}_{\mathrm{j}}}\left[\rho_{\mathrm{s}} \alpha_{\mathrm{s}}\left(\mathrm{V}_{\mathrm{i}} \mathrm{V}_{\mathrm{j}}+\beta_{\mathrm{ij}}\right)\right]= \\
& =\rho_{\mathrm{s}} \alpha_{\mathrm{s}} \mathrm{g}_{\mathrm{i}}+\mathrm{F}_{\mathrm{i}}+\frac{\partial}{\partial \mathrm{x}_{\mathrm{j}}}\left(\alpha_{\mathrm{s}} \sigma_{\mathrm{ij}}\right)+\frac{\partial}{\partial \mathrm{x}_{\mathrm{j}}}\left(\mathrm{s}_{\mathrm{ij}}\right)
\end{aligned}
$$

where $\beta_{\mathrm{ij}}$ denotes the components of the velocity cofluctuation tensor, gi stands for the components of the acceleration of gravity, and $F_{1}$ accounts for the gas-solids interaction force. Two stress tensors acting within the particles appear in this equation: $\sigma_{i j}$ accounts for the stresses linked by the fluid; while $s_{i j}$ is the probabilistic mean of intermittent stresses due to interparticle and/or wall-particle collisions. The momentum equation for the fluid is

$$
\begin{aligned}
& \frac{\partial}{\partial t}\left(\rho_{\mathrm{f}} \alpha_{\mathrm{f}} \mathrm{U}_{\mathrm{i}}\right)+\frac{\partial}{\partial \mathrm{x}_{\mathrm{j}}}\left[\rho_{\mathrm{f}} \alpha_{\mathrm{f}}\left(\mathrm{U}_{\mathrm{i}} \mathrm{U}_{\mathrm{j}}+\mathrm{B}_{\mathrm{ij}}\right)\right]= \\
& =\rho_{\mathrm{f}} \alpha_{\mathrm{r}} g_{\mathrm{i}}-\mathrm{F}_{1}-\frac{\partial}{\partial \mathrm{x}_{\mathrm{i}}}\left(\alpha_{\mathrm{f}} \mathrm{p}\right)+\frac{\partial}{\partial \mathrm{x}_{\mathrm{j}}}\left(\alpha_{\mathrm{f}} \tau_{\mathrm{ij}}\right)
\end{aligned}
$$

where $U_{i}$ and $B_{i j}$ denote, respectively, the components of gas velocity and the velocity cofluctuation tensor, $\mathrm{p}$ stands for the pressure, and $\tau_{i j}$ represents the components of viscous stresses acting within the fluid. In Equations (2) and (3), the LHS represents the inertial terms, while all the external forces acting on the phase are regrouped on the RHS.

An additional equation relates gas and solids presence probabilities:

$\alpha_{\mathrm{s}}+\alpha_{\mathrm{f}}=1$

These equations cannot be solved in general, since there is an obvious closure problem associated with them. 


\subsection{Fully developed vertical upflow of a suspension}

When a single-phase fluid flows at a constant rate in a straight pipe, the longitudinal pressure profile becomes linear beyond a certain distance downstream from the entrance; this situation corresponds to the establishment of flow patterns which are identical in each cross-section of the pipe, and is called fully developed flow. As reported by numerous authors e.g. refe. rences $15,13,8$ and 3 ) a similar situation is observed for suspension flows under similar conditions.

A rigorous definition based on the probabilistic Eulerian description has been given ${ }^{9)}$ for the fully developed flow of a gas-solids suspension. It follows from this definition that variables such $\alpha_{\mathrm{s}}, \alpha_{\mathrm{f}}, \mathrm{V}_{\mathrm{i}}, \mathrm{U}_{\mathrm{i}}, \beta_{\mathrm{ij}}$ and $\mathrm{B}_{\mathrm{ij}}$ are independent of the axial coordinate (denoted $\mathrm{x}$ ) throughout the fully developed flow region. Subsequently, the stress tensors $\mathrm{s}_{\mathrm{ij}}$ and $\tau_{\mathrm{ij}}$ are also $\mathrm{x}$-independent. In addition, if the suspension flows vertically in a pipe of circular cross-section, the radial velocity components $V_{\mathrm{r}}$ and $U_{\mathrm{r}}$ identically vanish in the fully developed flow region. Finally, in the absence of initial swirl, tangential velocity components $\mathrm{V}_{\theta}$ and $\mathrm{U}_{\theta}$ are identically zero throughout the flow.

The main general property of a fully developed suspension flow is that the longitudinal pressure gradient is independent of axial as well as transversal coordinates. This is a convenient property allowing an easy experimental identification of fully developed flow regions. Moreover, it has been shown ${ }^{9}$ that:

$$
-\frac{\partial \mathrm{p}}{\partial \mathrm{x}}=\frac{\partial}{\partial \mathrm{x}}\left(\sigma_{\mathrm{xx}}\right)=\mathrm{const} \text {. }
$$

Under fully developed flow conditions, Equations (2) and (3) simplify considerably. Adding through the axial projections of these momentum equations of both phases, combining with Equations (4) and (5), and integrating over a cross-section yields the following equation expressing the pressure gradient in a circular pipe (the vertical axis $\mathrm{Ox}$ is directed upwards):

$$
-\frac{\partial \mathrm{p}}{\partial \mathrm{x}}=-\frac{2}{\mathrm{R}}\left(\tau_{\mathrm{rx}}\right)_{\mathrm{w}}+\left[\rho_{\mathrm{s}} \mathrm{c}+\rho_{\mathrm{f}}(1-\mathrm{c})\right] \mathrm{g}-\frac{2}{\mathrm{R}}\left(\mathrm{srx}_{\mathrm{w}}\right)_{\mathrm{w}}(6)
$$

where $\mathrm{R}$ denotes the pipe radius and subscript $\mathrm{w}$ indicates that shearing stresses are evaluated at the wall; $\mathrm{c}$ is the cross-sectional average of $\alpha_{\mathrm{s}}$ defined by:

$\mathrm{c}=\frac{1}{\pi \mathrm{R}^{2}} \int_{0}^{\mathrm{R}} 2 \pi \mathrm{r} \alpha_{\mathrm{s}} \mathrm{dr}$

$c$ is therefore identified to the average volumetric concentration of particles over a cross-section.

Equation (6) confirms a result suggested by Hariu and Molstad ${ }^{4}$, according to which the pressure drop in a fully developed suspension flow is the sum of three contributions: the first term accounts for the wall friction of the gas, the second term represents the average weight of suspension per unit volume, while the third term corresponds to the contribution of wallparticle interactions.

The general conceptual framework of our probabilistic Eulerian description allows a partial modelling of the third term. As noted above, the $s_{i j}$ tensor, the shearing component of which appears in Equation (6), is due to interparticle and wall-particle collisions. As the term is evaluated at the wall where particle presence is reduced to points ${ }^{10)}$, the third term in Equation (6) is only due to wall-particle collisions. When an individual particle experiences a collision with the wall its loss of axial momentum is proportional to its actual axial momentum ${ }^{9,14}$, provided that the restitution coefficients applied to the normal and tangential velocity components remain constant. (This latter assumption has at least a statistical validity.) On the other hand, the collision frequency of a class of particles over a unit surface of wall is proportional to the local phase presence probability of the species. On the average, the wall shear stress due to wall-particle collisions can, therefore, be written in the form:

$$
\left(\mathrm{s}_{\mathrm{rx}}\right)_{\mathrm{w}}=-\mathrm{K}\left(\rho_{\mathrm{s}} \alpha_{\mathrm{s}} \mathrm{V}_{\mathrm{x}}\right)_{\mathrm{vw}}
$$

where the vw subscript means that the quantity is evaluated at the vicinity of the wall. The dimensional coefficient $\mathrm{K}$ depends upon the statistical distribution of transverse particle velocities in the wall region and is also a function of the thickness of the wall region from which, under the effect of their random radial velocities, the particles fly in the transverse 
direction to reach the wall and collide with it. According to Equation (8), the third term in Equation (6) is proportional to the mass flux of particles in the wall layer. It therefore allows a possible explanation for the "negative drag" problem: this effect could be due to a downflow of solids along the wall. Indeed, in this case, $\left(\mathrm{s}_{\mathrm{rx}}\right)_{w}$ becomes negative. The occurrence of this phenomena will be clearly illustrated by the experimental results presented below.

\subsection{Similar profiles regime}

If the flowrate of solids injected into the gas stream is progressively decreased to zero while the gas rate (or gas superficial velocity $U$ ) is maintained constant, the suspension flow tends toward a single-phase flow. This has been called reference flow $w^{9}$, since most of the authors compared their experimental results (pressure drop, gas velocity profiles, heat transfer coefficient, etc.) obtained with the suspension to those obtained with the gas alone flowing in the same installation with the same superficial velocity. When obtained as described above, the refer. ence flow is, therefore, the limiting case of a suspension in which solids concentration vanishes throughout the pipe. Consequently, fluid phase variables in the suspension such as $U_{i}$, $B_{i j}, \tau_{i j} \ldots$ should tend toward their values (noted with a 0 superscript) $\mathrm{U}_{1}^{0}, \mathrm{~B}^{0}{ }_{\mathrm{ji}}, \tau^{0}{ }_{\mathrm{ji}}$ in the reference flow as $c \rightarrow 0$, while all the terms in the solids phase equations tend toward zero. In addition, when $\mathrm{c}$ decreases to zero, $\boldsymbol{\alpha}_{\mathrm{s}} \rightarrow 0$ throughout the pipe according to Equation (7), subsequently, $\alpha_{\mathrm{f}} \rightarrow 1$ according to Equation (4). A reference flow variable such as e.g. $U_{i}{ }^{\circ}$, is thus the limiting value of both $U_{i}$ and $\alpha_{\mathrm{f}} U_{i}$ as $c \rightarrow 0$. By denoting $\psi_{i}$ as any one of the fluid phase variables and $\psi_{\mathrm{f}}{ }^{0}$ its limiting value, the following MacLaurin series development can, therefore, be used:

$\alpha_{\mathrm{f}} \psi_{\mathrm{f}}=\psi_{\mathrm{f}}^{0}+\mathrm{c} \psi_{\mathrm{f}}^{1}+\mathrm{O}\left(\mathrm{c}^{2}\right)$

In this equation, $\mathrm{c} \psi_{t}^{1}$ is the first order term and $O\left(c^{2}\right)$ represents the second and higher order terms of the power series development in terms of the average concentration $\mathrm{c}$.

When MacLaurin series developments analogous to (9) are substituted for the fluid phase variables appearing in the axial momentum equation of the fluid in the suspension, zeroth order terms (reference flow variables) drop and one obtains an equation relating first and higher order terms ${ }^{9)}$. Neglecting $\mathrm{O}\left(\mathrm{c}^{2}\right)$ as $\mathrm{c} \rightarrow 0$, a linear equation in terms of $\alpha_{s}$ and $c$ is obtained. It therefore follows from this latter equation that $\alpha_{\mathrm{s}}(\mathrm{r})$ is proportional to $\mathrm{c}$ throughout the cross-section of the pipe. An analogous approach is also applied to the solids momentum equation. (The details of the calculations can be found in references 9 and 11.) Finally, the following forms of solids concentration and velocity profiles appear as possible solutions to the equations of a fully developed suspension flow as $\mathrm{c} \rightarrow 0$.

$$
\begin{aligned}
& \alpha_{\mathrm{s}}(\mathrm{r} ; \mathrm{c} ; \mathrm{U})=\mathrm{cf}(\mathrm{r} ; \mathrm{U}) \\
& \mathrm{V}_{\mathrm{x}}(\mathrm{r} ; \mathrm{c} ; \mathrm{U})=\mathrm{V}_{\mathrm{x}}(\mathrm{r} ; \mathrm{U})
\end{aligned}
$$

Equations (10) and (11) define a particular flow structure called similar profiles regime. Indeed, it can easily be seen that at a constant gas superficial velocity, solids velocity $V_{\mathrm{x}}(\mathrm{r})$ and reduced concentration $\alpha_{\mathrm{s}}(\mathrm{r}) / \mathrm{c}$ profiles remain unchanged as the solids rate or average concentration is increased. This flow regime is expected to occur as $c \rightarrow 0$, i.e. under dilute-phase flow conditions. In other words, similar profiles could be the characteristic flow structure of dilute suspension flows.

Because of the closure problem evoked above, it is not possible at the present stage of our knowledge to completely solve the general equations of the gas-solids system even under fully developed flow conditions. The uniqueness of these asymptotic solutions cannot, therefore, be shown, nor is it possible to determine explicit expressions of the functions $\mathrm{f}(\mathrm{r} ; \mathrm{U})$ and $\mathrm{V}_{\mathrm{x}}(\mathrm{r} ; \mathrm{U})$ which remain unknowns. These two tasks should therefore be performed experimentally. As they indeed are, among the objectives of the experimental work presented below. Finally, neither the upper limit of applicability of the similar solutions, nor the properties of the flow structure in the denser regime which would succeed to the similar profiles cannot - for the moment - be derived from the theory summarized above.

The possible existence of similar solutions allows the derivation of an explicit expression directly comparable to experimental measure- 
ments for the pressure drop. The first term in the RHS of Equation ${ }^{6)}$ which accounts for the wall friction of the gas in the suspension flow cannot be directly measured. However, an asymptotic expression of this term can be obtained in the similar profiles regime using for $\alpha_{\mathrm{f}} \tau_{\mathrm{rx}}$ a MacLaurin series development of the form defined by Equation (9):

$\alpha_{\mathrm{f}} \tau_{\mathrm{rx}}=\tau_{\mathrm{rx}}^{0}+\mathrm{c} \tau_{\mathrm{rx}}^{1}+\mathrm{O}\left(\mathrm{c}^{2}\right)$

Substituting for this expression evaluated at the wall in Equation (6) combined with Equation (8), subtracting the pressure gradient of the reference flow, and finally, neglecting the second order term $\mathrm{O}\left(\mathrm{c}^{2}\right)$ leads to the following equation defining the "additional pressure drop" (i.e. the change in pressure drop due to the solids) for a fully developed vertical upflow of a gas-solids suspension

$$
\begin{aligned}
& -\frac{\partial \mathrm{p}^{1}}{\partial \mathrm{x}}=-\frac{\partial \mathrm{p}}{\partial \mathrm{x}}+\frac{\partial \mathrm{p}^{0}}{\partial \mathrm{x}}= \\
& =\mathrm{c}\left[-\frac{2}{\mathrm{R}}\left(\tau_{\mathrm{rx}}^{1}\right)_{\mathrm{w}}+\left(\rho_{\mathrm{s}}-\rho_{\mathrm{f}}\right) \mathrm{g}\right]+\frac{2 \mathrm{~K}}{\mathrm{R}}\left(\rho_{\mathrm{s}} \alpha_{\mathrm{s}} \mathrm{V}_{\mathrm{x}}\right)_{\mathrm{vw}}
\end{aligned}
$$

It should be noted that in the similar profiles regime, according to Equations (10) and (11), the last term in the RHS of Equation (13) is also proportional to $\mathrm{c}$. Consequently, the additional pressure drop will be, at a constant gas superficial velocity, strictly proportional to the average solids concentration $c$.

Another relationship which can be deduced from the similar profiles is the one between the solids rate $W_{\mathrm{s}}$ and the average concentration:

$$
\begin{aligned}
& \mathrm{W}_{\mathrm{s}}=\int_{0}^{\mathrm{R}} 2 \pi \mathrm{r} \rho_{\mathrm{s}} \alpha_{\mathrm{s}} \mathrm{V}_{\mathrm{x}} \mathrm{dr}= \\
& =\rho_{\mathrm{S}} \mathrm{c} \int_{0}^{\mathrm{R}} 2 \pi \mathrm{rf}(\mathrm{r} ; \mathrm{U}) \mathrm{V}_{\mathrm{x}}(\mathrm{r} ; \mathrm{U}) \mathrm{dr}
\end{aligned}
$$

Therefore, in the similar profiles regime, the solids mass flowrate $\mathrm{W}_{\mathrm{s}}$ is also strictly proportional to the average concentration $c$ at a constant superficial gas velocity U. As a consequence, the average solids velocity $\mathrm{V}$ defined by:

$\mathrm{V}=\frac{\mathrm{W}_{\mathrm{S}}}{\rho_{\mathrm{S}} \mathrm{c} \pi \mathrm{R}^{2}}$

depends only on $\mathrm{U}$ for a given gas-solids system flowing in a given pipe. Moreover, a local slip
- or relative - velocity can be defined for the solids:

$V_{\text {rel }}(r)=U_{x}(r)-V_{x}(r)$

By combining Equations (4), (7), (10), (11) and (15) together with a MacLaurin series development for $\mathrm{U}_{\mathrm{x}}$, and by applying the asymptotic simplifications according to which $\mathrm{c}^{\mathrm{n}}$ is negligible compared to $\mathrm{c}^{\mathrm{n}-1}$, the following expression can be found for the average solids velocity

$$
\pi \mathrm{R}^{2} \mathrm{~V}=\int_{0}^{\mathrm{R}} 2 \pi \mathrm{rf}(\mathrm{r}) \mathrm{U}_{\mathrm{x}}^{0}(\mathrm{r})-\int_{0}^{\mathrm{R}} 2 \pi \mathrm{rf}(\mathrm{r}) \mathrm{V}_{\mathrm{rel}}(\mathrm{r}) \mathrm{dr}
$$

When - in an experimental installation - W, and $c$ are simultaneously and independently measured, it is possible to find the relationship between $\mathrm{V}$ and $\mathrm{U}$ for the gas-solids system under consideration flowing in that particular pipe. The analysis of this relationship with the help of Equation (17) can yield some qualitative information about the reduced concentration profile $f(r ; U)$. Indeed, since the velocity field of the reference flow $U_{x}^{0}(r)$ is that of a - generally turbulent - single-phase flow, it is essentially proportional to U. Therefore,

(a) if $f(r)$ is independent of $U$ (or only slightly dependent on $U$ within a limited range), the first integral in the RHS of Equation (17) can be written as $\pi \mathrm{R}^{2} \mathrm{C}_{0} \mathrm{U}$ where $\mathrm{C}_{0}$ is a dimensionless constant. Moreover,

(b) if the concentration profile is essentially uniform throughout the cross-section, in other words, if $\mathrm{f}(\mathrm{r}) \equiv 1$, the constant $\mathrm{C}_{0}$ will take on the value of 1 . On the other hand, if condition (a) is satisfied and, in addition,

(c) if Vrel(r) is also independent of the superficial gas velocity, the second integral in the RHS of Equation (17) can be written as $\pi \mathrm{R}^{2} \mathrm{C}_{1}$, where $\mathrm{C}_{1}$ is a constant equivalent to a velocity. Finally, if condition (b) holds and if, in addition, (d) $\mathrm{V}_{\mathrm{rel}}(\mathrm{r})$ is uniform over the cross-section and equal e.g. to the average terminal velocity $\mathrm{Vt}$ of the particles, one would have $C_{1}=V_{t}$.

It should be noted, however, that none of the conditions (a) to (d) listed above are rigorously necessary conditions, and that conclusions deduced from particular values taken on by $\mathrm{C}_{0}$ and $\mathrm{C}_{1}$ cannot therefore be considered as unquestionably evidenced. Nevertheless, the above argument gives an interesting sketch for interpretation since it allows the deduction of 
presumably valid properties, especially concerning the solids concentration profiles, from overall measurements.

\subsection{Thermally fully developed flow}

For the analysis of heat transfer in gas-solids suspensions, specific energy equations are derived for each phase using the probabilistic Eulerian description of multiphase mixtures ${ }^{9}$. When radiation is negligible and temperature differences in the installation moderate, the energy equation of the solids phase takes the following form

$$
\begin{aligned}
& \frac{\partial}{\partial \mathrm{t}}\left(\rho_{\mathrm{s}} \mathrm{C}_{\mathrm{s}} \alpha_{\mathrm{s}} \mathrm{T}_{\mathrm{s}}\right)+\frac{\partial}{\partial \mathrm{x}_{\mathrm{i}}}\left[\rho_{\mathrm{s}} \mathrm{C}_{\mathrm{s}} \alpha_{\mathrm{s}}\left(\mathrm{T}_{\mathrm{s}} \mathrm{V}_{\mathrm{i}}+\varepsilon_{\mathrm{s}}^{\mathrm{s}}\right)\right]= \\
& =\frac{\partial}{\partial \mathrm{x}_{\mathrm{i}}}\left[\lambda_{\mathrm{s}} \frac{\partial}{\partial \mathrm{x}_{\mathrm{i}}}\left(\alpha_{\mathrm{s}} \mathrm{T}_{\mathrm{s}}\right)-\lambda_{\mathrm{s}} \mathrm{T}_{\mathrm{I}} \frac{\partial \alpha_{\mathrm{s}}}{\partial \mathrm{x}_{\mathrm{i}}}\right]+\mathrm{Q}_{\mathrm{fs}}
\end{aligned}
$$

where $T_{\mathrm{s}}$ stands for the local solids temperature, $\mathrm{C}_{\mathrm{s}}$ for the specific heat capacity of the particles, and $\lambda_{\mathrm{s}}$ for the thermal conductivity of the particles; $\varepsilon$ idenotes the components of the temperature-velocity cofluctuation vector, and $T_{1}$ represents the "interfacial mean temperature" ${ }^{1,10)}$ which expresses in fact, the continuity of immediate Eulerian temperature fields at the interface. Finally, $Q_{\mathrm{fs}}$ accounts for the heat transferred from the fluid to the solids per unit time and unit volume of suspension. An analogous equation is derived for the fluid:

$$
\begin{aligned}
& \frac{\partial}{\partial t}\left(\rho_{\mathrm{f}} \mathrm{C}_{\mathrm{f}} \alpha_{\mathrm{f}} \mathrm{T}_{\mathrm{f}}\right)+\frac{\partial}{\partial \mathrm{x}_{\mathrm{i}}}\left[\rho_{\mathrm{f}} \mathrm{C}_{\mathrm{f}} \alpha_{\mathrm{f}}\left(\mathrm{T}_{\mathrm{f}} \mathrm{U}_{\mathrm{i}}+\varepsilon \mathrm{f}\right)\right]= \\
& =\frac{\partial}{\partial \mathrm{x}_{\mathrm{i}}}\left[\lambda_{\mathrm{f}} \frac{\partial}{\partial \mathrm{x}_{\mathrm{i}}}\left(\alpha_{\mathrm{f}} \mathrm{T}_{\mathrm{f}}\right)-\lambda_{\mathrm{f}} \mathrm{T}_{\mathrm{l}} \frac{\partial \alpha_{\mathrm{f}}}{\partial \mathrm{x}_{\mathrm{i}}}\right]-\mathrm{Q}_{\mathrm{fs}}
\end{aligned}
$$

Equations (18) and (19) illustrate the great complexity of heat transfer mechanisms in a gassolids suspension. Apart from the well known convective transport (first term within square brackets in the LHS), diffusional transport (second term) due to the random motion of the phases combines with transfer by conduction through the phases (first term within square brackets in the RHS). Besides this, the two equations are coupled through two variables $T_{1}$ and $\mathrm{Q}_{\mathrm{fs}}$ which account respectively for temperature and heat flux jump conditions at the interface.

A thermally fully developed flow can be defined in the case of the rectilinear pipe flow of a suspension, provided that the two following conditions are simultaneously satisfied ${ }^{9,12)}$. (i) the suspension flow is dynamically fully developed;

(ii) the heat flux provided to the suspension by the wall $\varphi_{\mathrm{w}}$ is uniform throughout the wall.

As a consequence, the radial temperature profiles of either the solids, the fluid or the interface are independent of the axial coordinate $x$ and the axial gradients of both $T_{s}, T_{f}$ and $T_{t}$ are identical and equal to the gradient of the wall temperature $T_{w}(x)$. Finally, the latter is related to $\varphi_{\mathrm{w}}$ through the heat balance equation

$2 \pi \mathrm{R} \varphi_{\mathrm{w}}=\left(\mathrm{W}_{\mathrm{s}} \mathrm{C}_{\mathrm{s}}+\mathrm{W}_{\mathrm{f}} \mathrm{C}_{\mathrm{f}}\right) \frac{\mathrm{d} \mathrm{T}_{\mathrm{W}}}{\mathrm{dx}}$

A "mixed mean temperature" can be defined either for the gas, the solids or the mixture. The latter is generally used when representing heat transfer to gas-solids suspensions ${ }^{15}$. The difference between local wall temperature and the mixture's mixed mean temperature $\mathrm{T}_{\mathrm{mm}}$ is defined by the following equation

$$
\begin{aligned}
& \left(\mathrm{W}_{\mathrm{s}} \mathrm{C}_{\mathrm{s}}+\mathrm{W}_{\mathrm{f}} \mathrm{C}_{\mathrm{f}}\right)\left(\mathrm{T}_{\mathrm{w}}-\mathrm{T}_{\mathrm{mM}}\right)= \\
& =\int_{0}^{\mathrm{R}} 2 \pi \mathrm{r}\left[\rho_{\mathrm{s}} \mathrm{C}_{\mathrm{s}} \alpha_{\mathrm{s}}\left(\mathrm{T}_{\mathrm{w}}-\mathrm{T}_{\mathrm{s}}\right)+\rho_{\mathrm{f}} \mathrm{C}_{\mathrm{f}} \alpha_{\mathrm{f}}\left(\mathrm{T}_{\mathrm{w}}-\mathrm{T}_{\mathrm{f}}\right)\right] \mathrm{dr}
\end{aligned}
$$

The temperature difference $\Delta T_{m}^{*}=\left(T_{w}-T_{m M}\right)$ is used as the reference temperature difference for the definition of a heat transfer coefficient for the gas-solids mixture :

$h_{\mathrm{m}}=\frac{\varphi_{\mathrm{w}}}{\Delta \mathrm{T}_{\mathrm{m}}}$

\subsection{Similar profiles regime and wall- to $^{-}$ suspension heat transfer coefficient}

An analysis of the asymptotic behaviour of the temperature fields in the suspension analogous to that presented in $\S 2.3$ can be achieved in the range of the similar profiles regime. In order to match the requirements of limiting values reached continuously, the temperature field of the reference flow must be defined as that of the reference flow heated under the same thermal boundary conditions as the suspension, i.e. the same inlet temperature and the same wall heat flux $\varphi_{\mathrm{w}}$. The heat transfer coefficient $h_{0}$ of the reference flow is then defined as :

$h_{0}=\frac{\varphi_{\mathrm{w}}}{\Delta \mathrm{T}_{\mathrm{f}}^{0}}$ 
where the reference temperature difference $\Delta \mathrm{T}_{\mathrm{f}}^{\circ}=\left[\mathrm{T}_{\mathrm{w}}^{o}(\mathrm{x})-\mathrm{T}_{\mathrm{fM}}^{0}(\mathrm{x})\right]$ is defined by the limiting form of Equation (21) as $\mathrm{c} \rightarrow 0$.

Denoting $\theta_{\mathrm{p}}(\mathrm{r})=\mathrm{T}_{\mathrm{w}}(\mathrm{x})-\mathrm{T}_{\mathrm{p}}(\mathrm{x}, \mathrm{r})$, the radial temperature profiles for either the fluid $(p=f)$, the solids $(p=s)$ or the interface $(p=I)$, the following asymptotic forms are obtained as $\mathrm{c} \rightarrow 0$. (The details of the mathematical argument can be found in references 9,15 and 12.)

$$
\begin{aligned}
& \alpha_{\mathrm{f}} \theta_{\mathrm{f}}=\theta_{\mathrm{f}}^{\mathrm{o}}(\mathrm{r} ; \mathrm{U})+\frac{\mathrm{c} \theta_{\mathrm{f}}^{1}(\mathrm{r} ; \mathrm{U})}{1+\Gamma}+\mathrm{O}\left(\mathrm{c}^{2}\right) \\
& \alpha_{\mathrm{s}} \theta_{\mathrm{s}}=\frac{\mathrm{c} \theta_{\mathrm{f}}^{\mathrm{l}}(\mathrm{r} ; \mathrm{U})}{1+\Gamma}+\mathrm{O}\left(\mathrm{c}^{2}\right) \\
& \theta_{\mathrm{I}}=\frac{\theta_{\mathrm{I}}^{\mathrm{o}}(\mathrm{r} ; \mathrm{U})}{1+\Gamma}+\mathrm{O}\left(\mathrm{c}^{2}\right)
\end{aligned}
$$

where $\Gamma$ is defined by the ratio:

$\Gamma=\frac{\mathrm{W}_{\mathrm{s}} \mathrm{C}_{\mathrm{s}}}{\mathrm{W}_{\mathrm{f}} \mathrm{C}_{\mathrm{f}}}$

It is noteworthy that the asymptotic form of $\alpha_{\mathrm{f}}$ $\theta_{\mathrm{f}}$ differs from that predicted by Equation (9) for hydrodynamic variables by a factor $(1+\Gamma)$. In fact, this scaling factor appears in Equations (24) to (26) because the heat capacity per unit volume of the flow increases by a factor $(1+\Gamma)$ when the solids are loaded into the gas stream.

The self-similar temperature profiles defined by Equations (24) and (25) can be used together with Equations (21) to (23) to calculate the variation of the heat transfer coefficient with solids loading. One obtains the following form

$$
\frac{\mathrm{h}_{\mathrm{m}}}{\mathrm{h}_{0}}=\frac{(1+\Gamma)^{2}}{1+\mathrm{a} \Gamma+\mathrm{b} \Gamma^{2}}
$$

where $\mathrm{a}$ and $\mathrm{b}$ are compound shape factors combining cross-sectional integrals of the reduced concentration, velocity and temperatures profiles of the phases as characterizing the similar profiles. As a consequence, for a given gas-solids system flowing in a given pipe, $a$ and $b$ are functions of only one variable: the superficial gas velocity $U$ which determines the hydrodynamics of the suspension flow.

Dependent upon the values taken on by $a$ and $b$, six different trends of variation of $\mathrm{hm}$ with the solids loading ratio $W_{\mathrm{s}} / \mathrm{W}_{\mathrm{f}}$ can be predicted ${ }^{12)}$.
At least three of them have already been observed by previous authors. In other words, Equation (28) predicts all the apparently contradictory trends of variation summarized by Maeda et al. ${ }^{5)}$, and which were not yet explained.

\section{Experimental}

\subsection{Experimental installations}

Experiments have been carried out on two different installations. Both contain a vertical column with an overall height exceeding $10 \mathrm{~m}$. The first installation is a pneumatic transport line which has a small diameter $(20 \mathrm{~mm}$ ID) in order to enhance wall effects such as they can be accurately measured and compared to the predictions of Equation (13). It is equipped with complete instrumentation for gas and solids flowrates, axial pressure gradient and average solids concentration measurements. Besides this, the test section can be replaced by a heating section in order to permit measurement of heat transfer coefficients. The second installation is a circulating fluidized bed column of 144 mm ID equipped with a non-isokinetic sampling probe which allows determination of radial particle mass flux profiles in the fully developed flow section.

In the pneumatic transport installation Fig. 1, the solids are injected into the gas stream by means of a fluidized bed feeder. The base of the transport line enters the bed and is submerged in the fluidized solids. Small holes drilled around the circumference of the submerged section allow the solids to flow from the bed into the line at a rate finely controlled by varying either the pressure above the bed or the bed height. At the outlet of the line, the suspension flows through a disengaging chamber where most of particles are recovered, followed by a cyclone for final cleaning. Recovered solids are recycled into the fluidized bed feeder by means of a standpipe. Gas flowrate is measured by a rotameter placed at the outlet of the cyclone, while the solids flowrate is determined by collecting the recycled solids over measured time intervals. The stainless steel transport line is divided into 3 sections: a $4.5 \mathrm{~m}$ acceleration zone, a $4.2 \mathrm{~m}$ test section, and a $2.5 \mathrm{~m}$ disengaging area. Two pneumatically activated slide valves are placed at the top and bottom of the test section. The simultaneous closing of these valves allows the mean solids concentration in 


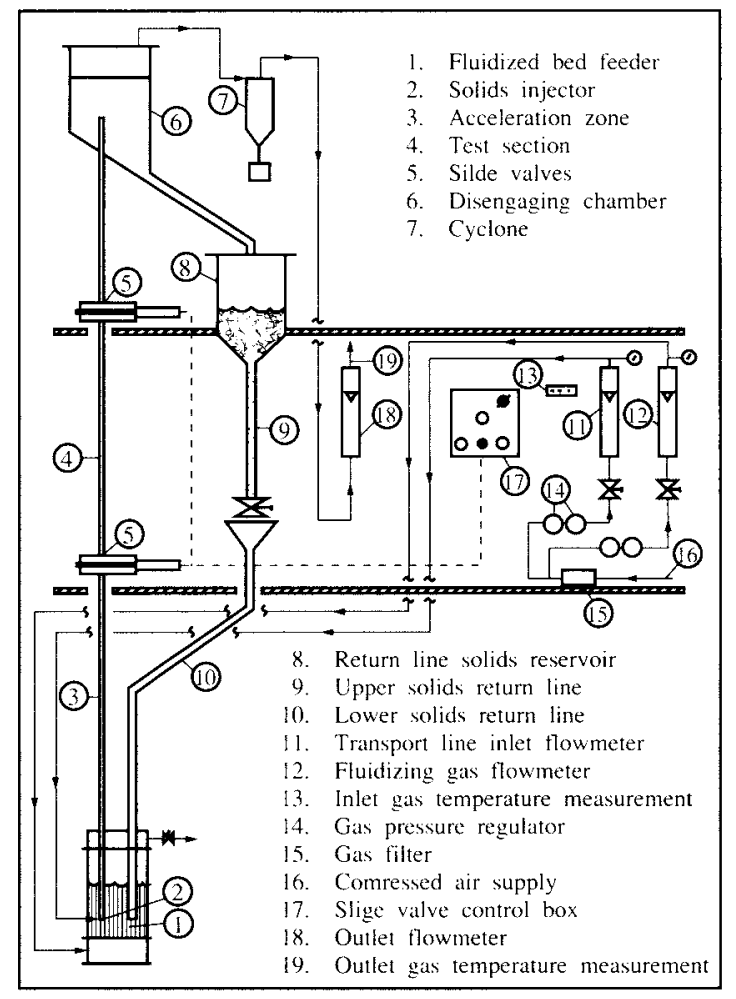

Fig. 1 Pneumatic transport installation $(20 \mathrm{~mm} \mathrm{ID})$.

the test section to be measured. Finally, 21 wall pressure taps connected to water manometers allow accurate determination of the axial distribution of pressure along the transport line.

For heat transfer measurements, a heating section consisting of a thin-walled $(0.5 \mathrm{~mm}), 20$ $\mathrm{mm}$ ID stainless steel pipe specially drawn to ensure even wall thickness was inserted between the slide valves. Copper flanges are silver-soldered at each end of the pipe and the pipe is heated by applying a DC supply between the flanges. Heat input into the system is determined by measuring the voltage across the pipe and the current in the circuit. Wall surface temperatures are measured using platinium resistance thermometers placed at intervals of $250 \mathrm{~mm}$ along the pipe length. The heat transfer section is insulated with fiber-glass insulation to minimize radial losses. Axial losses by conduction along the wall pipe are minimized by the low thickness of the pipe wall. Overall, the losses are less than $10 \%$ of the heat input, and the system supplies an essentially uniform heat flux to the suspension. Additional" details concerning the installation and operating procedure can be found in Muzyka ${ }^{15}$.
The second installation Fig. 2, is a circulating fluidized bed consisting of a riser column, a particle collection system and a solids return line. The $0.144 \mathrm{~m}$ ID plexiglass riser is equipped with 16 wall pressure taps connected to water manometers. The particle collection system combines in series a disengaging chamber, two cyclone stages, and a bag filter for final clean. ing when fine particles are used. The particles collected by the disengaging chamber and the cyclones flow by gravity into a weighing hopper standing on three force transducers, and then into the buffer hopper through a pneumatically closing valve. The latter feeds by gravity a nonmechanical L-valve system by means of which the solids are re-injected into the riser, at the throat of a Venturi nozzle. The circulating solids rate is finely controlled by the aeration rate supplied at the elbow of the $\mathrm{L}$-valve. This solids rate is determined by closing the outlet

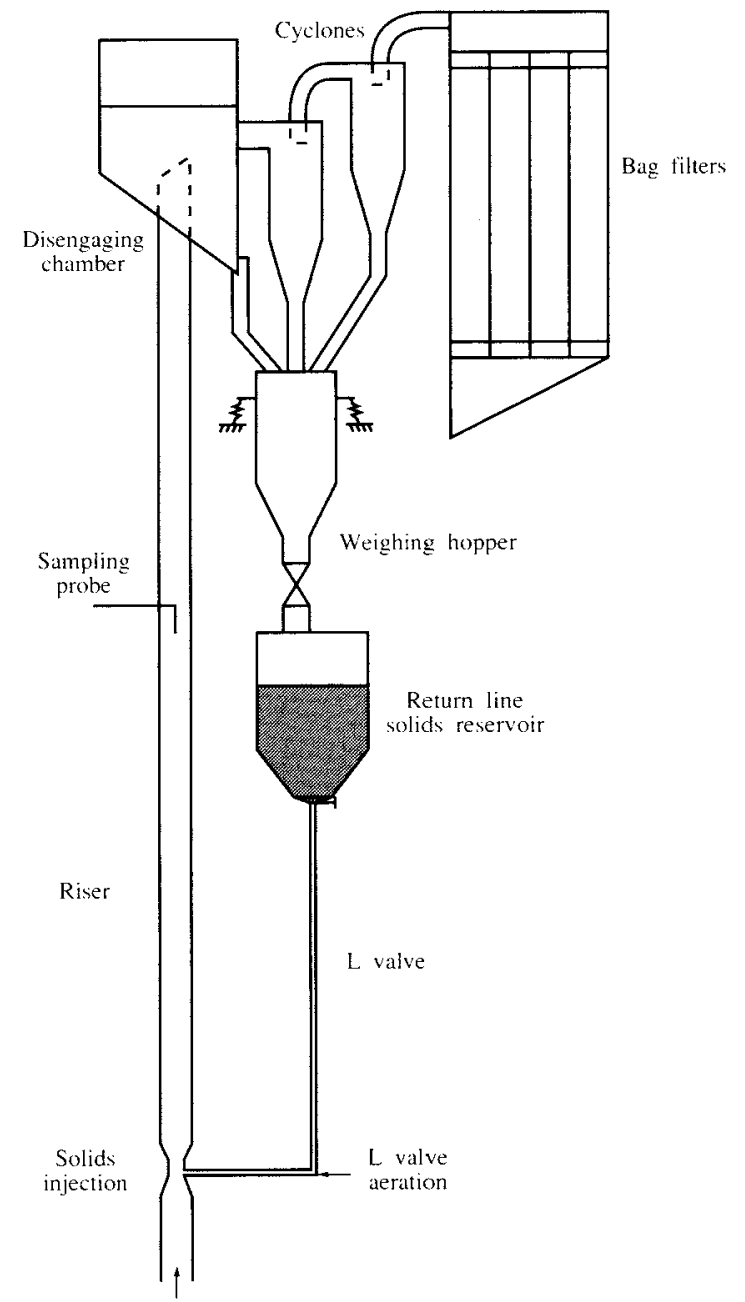

Fig. 2 Schematic diagram of the circulating fluidized bed installation (144 mm ID). 
pneumatic valve of the weighing hopper and monitoring the increase in weight indicated by the force transducers over time intervals of about one minute. The carrying gas rate is measured by means of an orifice plate located upstream from the Venturi nozzle. L-valve aeration rate is determined by a rotameter. Additional details can be found in Monceaux ${ }^{13)}$.

Particle mass flux profiles are determined by means of a non-isokinetic sampling probe developed by $\mathrm{Azzi}^{1}$, and shown schematically in Fig. 3. It consists of a steel tube (4 mm ID ; 6 $\mathrm{mm}$ OD) bent at $90^{\circ}$ and connected to a suction circuit which has two identical branches in parallel, each equipped with a particle collecting box, and both connected to the same vacuum pump. The pump is operated continuously in order to allow steady state sampling condi-

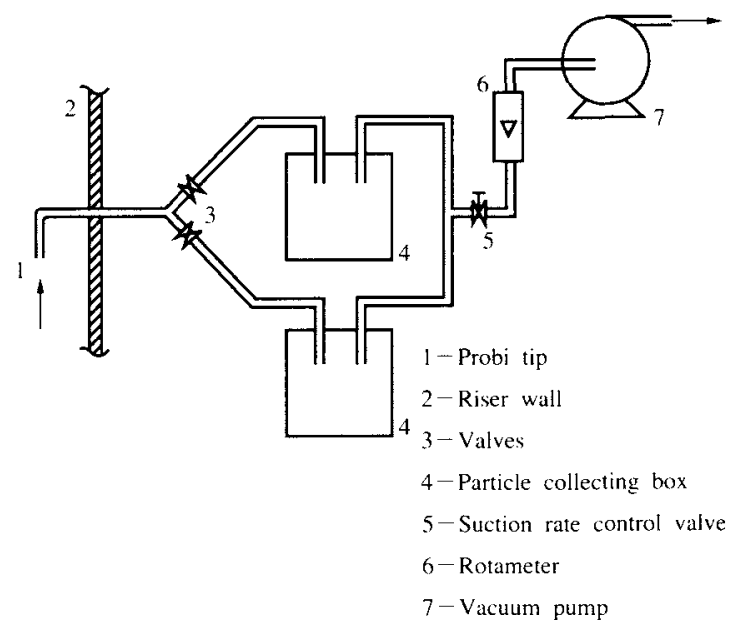

Fig. 3 Schematic diagram of the non-isokinetic sampling system.

tions and the indrawn suspension flows either through the first branch of the circuit or is diverted toward the second branch over measured time intervals for particle mass flux measurements. The axis of the tapered nose of the probe is maintained vertical, and can be turned by $180^{\circ}$ in order to collect the downflowing particle flux especially in the wall region. The probe is located at $4 \mathrm{~m}$ above the solids injection section, and sampling is therefore always performed in the fully developed flow region. The radial position of the probe tip can be varied at will in order to scan a diameter of the column for determining the radial profile of particle mass fluxes. The technique is called "non-isokinetic" sampling, since Azzi showed that measured particle fluxes remain essentially constant when suction velocity is varied within a range of at least $\mathrm{xxx} 1.5 \mathrm{~m} / \mathrm{s}$ around the superficial gas velocity in the riser.

\subsection{Hydrodynamics of dilute-phase flow}

The overall hydrodynamic properties of dilute suspension flows have been studied using both installations. In all cases $^{15,13,8,3)}$, a fully developed flow region with its characteristic linear-axial pressure profile has been found at distances downstream from the solids feed section which do not exceed $3 \mathrm{~m}$.

\section{Pressure drop}

Muzyka ${ }^{15)}$, investigated the relationship between pressure drop and average solids concentration under fully developed flow conditions for three different solids. A typical set of data obtained in these experiments carried out in the $20 \mathrm{~mm}$ pneumatic transport installation is shown in Fig. 4, where axial pressure gradients (at three different gas velocities) are plotted against correponding average solids concentrations of sand particles $\left(\rho_{\mathrm{s}}=2630 \mathrm{~kg} / \mathrm{m}^{3}\right)$ with a Sauter mean diameter of $172 \mu \mathrm{m}$. As predicted by Equation (13), at constant superficial gas velocity straight lines are obtained, the intercepts of which are equal to the pressure drops of their respective reference flows (i.e. the flow of the gas alone with the same superficial velocity $U$ ). The linear trend of variation of the "additional" pressure drop with average solids concentration c seen in Fig. 4 suggests that the

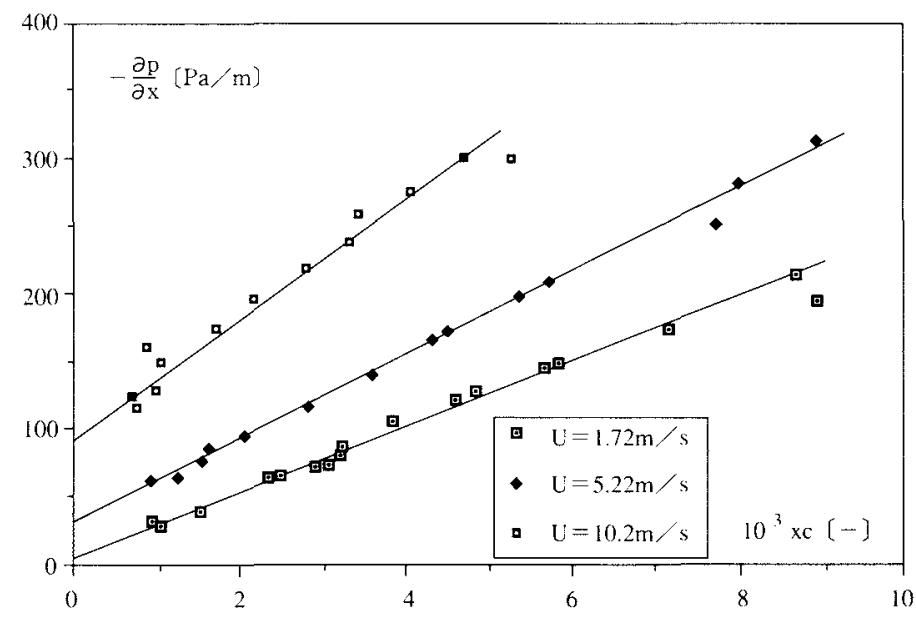

Fig. 4 Pressure drop as a function of average solids concentration at different superficial gas velocities for $172 \mu \mathrm{m}$ sand particles, as per Muzyka [15] . 
similar profiles regime assumption is valid since, in this case, the last term in Equation (13) becomes also proportional to $\mathrm{c}$ as predicted by Equations (10) and (11).

The trend of variation of the slopes of the straight lines with $U$ is shown in Fig. 5 for the same particles. As can be seen, the slope of the lines increases with $U$ but is lower than $\left(\rho_{\mathrm{s}}-\rho_{\mathrm{f}}\right) \mathrm{g}$ at low superficial gas velocity (approx. $U<$ $2.3 \mathrm{~m} / \mathrm{s}$ ). This illustrates the so-called negative drag effect. According to Equation (13), it should be attributed to either gas or particle wall friction terms. If the observed negative drag was due predominantly to the change in the viscous shear stress at the wall, to match the data obtained e.g. for $U=1.72 \mathrm{~m} / \mathrm{s}, \quad\left(\tau_{\mathrm{rx}}^{1}\right)_{\mathrm{w}}$ should amount as high as about - 350 times $\left(\tau_{\mathrm{rx}}^{0}\right)_{\mathrm{w}}$, or in other words, for an average solids concentration of $c=0.01$, the actual gas velocity in the wall region should be equal to about 2.5 times its value in the reference flow. Obviously, such a situation is highly unlikely. Therefore, it should be considered that the negative drag as well as the difference between the slope of the additional pressure drop curve and $\left(\rho_{\mathrm{s}}-\right.$ $\left.\rho_{\mathrm{f}}\right) \mathrm{g}$ is predominantly due to the last term in Equation (13). Moreover, particle mass flux profiles reported by Azzi which will be discussed below confirm this interpretation. Indeed, particle fluxes measured near the wall increase with $U$ and negative fluxes exist at low gas superficial velocity. Therefore, these observations confirm that Equation (13) is a sound basis for the interpretation of the pressure drop of dilute vertical gas-solids suspensions under fully developed flow conditions.

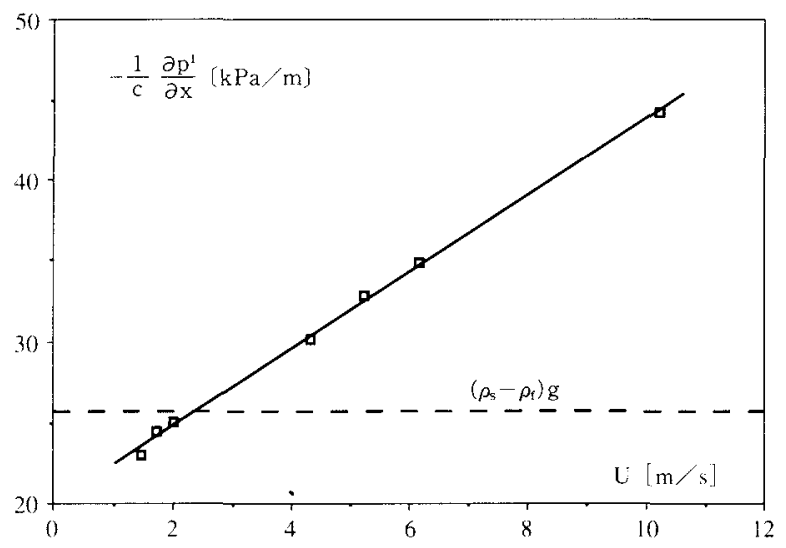

Fig. 5 Variation of the slopes of additional pressure drop curves with superficial gas velocity for $172 \mu \mathrm{m}$ sand particles, as per Muzyka [15] ; the dashed line represents the gravity term.
Most of the authors dealing with vertical gassolids have more or less intuitively considered that in large diameter risers, the unit pressure drop divided by $\left(\rho_{\mathrm{s}}-\rho_{\mathrm{f}}\right) \mathrm{g}$ is approximately equal to the average solids concentration $c$. The validity of this approximation can be analysed on the basis of Equation (13). Indeed, the contribution of gas wall-shear stress to pressure drop decreases as $1 / R$ and can be considered as negligible compared to solids hold-up in large diameter columns. Moreover, Equation (13) similarly suggests that the contribution of the third term (wall-particle interaction) will also become negligible as pipe radius is increased. This latter argument, however, considers implicitly that the compound $\mathrm{K}\left(\rho_{\mathrm{s}} \alpha_{\mathrm{s}} V_{\mathrm{x}}\right)_{\mathrm{w}} / \mathrm{c}$ retains its order of magnitude at a given gas velocity in large and small diameter risers. This requires, e.g., that the dimensionless profiles defined by Equations (10) and (11), re-written as functions of the reduced radial distance $r / R$, become independent of pipe radius. To our knowledge, such a property has not yet been reported based on experimental evidence. Besides, if Muzyka's data are considered for scaling-up calculations, it should be recalled that the solids velocity profiles, and especially the values taken on by $V_{x}$ at the wall for a given gas-solids system, depend also on the geometrical (roughness) and physical properties of the wall ${ }^{11)}$, since wall-particle collisions define a boundary condition for $V_{x}$ at the wall.

Muzyka's findings have been confirmed by the experimental results of $\mathrm{Mok}^{8)}$ and Bentahar ${ }^{3)}$. The conclusions of the above discussion can, therefore, be generalized and summarized as follows. The pressure drop of a vertical, dilute phase, fully developed flow of a gas-solids suspension is the sum of three contributions: gas wall friction, gravity, wall-particle interactions. The first term is essentially equal to the pressure drop of the gas alone flowing in the same pipe with the same superficial velocity (reference flow); the gravity term accounts for the average apparent weight of the particles per unit volume of pipe; and wall-particle interactions are proportional to the axial solids mass flux in the wall layer. As a result, the "additional" pressure drop is proportional to average solids concentration at constant gas superficial velocity. The difference between additional 
pressure drop and solids hold-up is essentially due to the wall-particle interaction term from which "negative drag" results when a downflow of solids exists in the wall layer.

\section{Similar profiles}

As noted in $\$ 2.3$, similar profiles defined by Equations (10) and (11) are possible asymptotic solutions to general equations. The effective existence of a similar profiles regime under dilute-phase fully developed flow conditions has been experimentally shown by $\mathrm{Azzi}{ }^{11}$. His experiments were carried out using cracking catalyst particles $\left(\rho_{\mathrm{s}}=900 \mathrm{~kg} / \mathrm{m}^{3}\right)$ with a Sauter mean diameter of $60 \mu \mathrm{m}$ in the circulating fluidized bed installation. The radial profiles of net axial particle mass fluxes were determined using the non-isokinetic sampling probe described above. (The net flux is the difference between upflowing and downflowing fluxes.) A typical set of data obtained by varying solids concentration at three different levels of superficial gas velocity is plotted in Fig. 6 in dimensionless form. As can be clearly seen from Fig. 6 , the radial profiles of particle mass fluxes divided by their cross-sectional averages are independent of solids loading at a constant gas velocity. This is, therefore, in complete agreement with the predictions of Equations (10) and (11).

These similar mass flux profiles deform when gas velocity is increased. A downward directed net particle flow in the wall region is clearly observed at low gas velocity as evoked above in the negative-drag discussion. Moreover, particle fluxes in the vicinity of the wall increase as superficial gas velocity increases. Finally, it should be noted that with the gas-solids system under consideration, similar profiles exist up to volumetric solids concentrations as high as 0.04 or slightly more. This observation gives a first indication of the range of applicability of asymptotic similar solutions and suggests that several industrial installations are operated in the similar profiles regime. All dimensionless similar mass flux profiles determined in this case intersect at a radial distance corresponding approximately to $50 \%$ of the cross-sectional area of the riser. Besides this, Azzi attempted to correlate his results within a unique equation. He found that a correlation of the form:

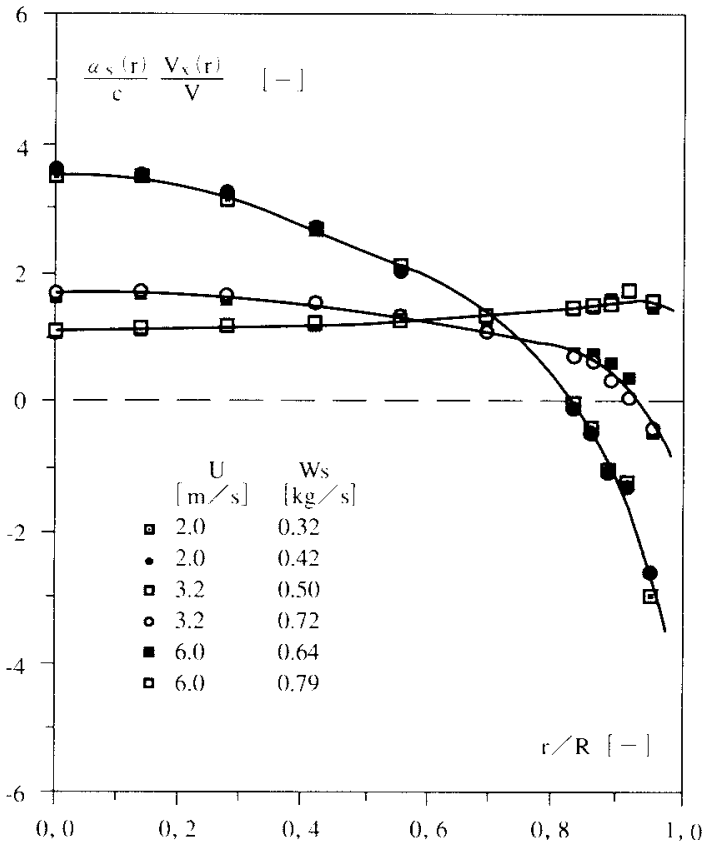

Fig. 6 Reduced solids mass flux profiles for $60 \mu \mathrm{m}$ cracking catalyst particles, as per Azzi [1].

$\frac{\alpha_{\mathrm{S}} \mathrm{V}_{\mathrm{x}}}{\mathrm{cV}}=\mathrm{B}(\mathrm{r})-\frac{\mathrm{A}(\mathrm{r})}{\mathrm{U}}$

accounts very well for the effect of gas velocity in the range $2 \mathrm{~m} / \mathrm{s}<U<6 \mathrm{~m} / \mathrm{s} . \mathrm{A}(\mathrm{r})$ and $\mathrm{B}(\mathrm{r})$ are quadratic functions of radial distance $r$; but he failed in finding a unique expression valid throughout the cross-section for each of these functions. In fact, on each side of the intersection point, the numerical coefficients of these functions assume essentially different values. However, the ratio $\mathrm{A}(\mathrm{r}) / \mathrm{B}(\mathrm{r})$ can be considered in all these cases as being essentially constant and equal to $4.3 \mathrm{~m} / \mathrm{s}$. This observation suggests that for this particular value of the superficial gas velocity, the mass flux profiles are essentially uniform over a cross-section. Indeed, it can be seen from his detailed results ${ }^{11}$, that the concavity of radial mass flux profiles changes when increasing superficial velocities pass through this value of $4.3 \mathrm{~m} / \mathrm{s}$.

\section{Average solids velocity and in-line particle size distribution}

Analysing the trend of variation of the solids rate $W_{\mathrm{s}}$ and average particle concentration $\mathrm{c}$, Muzyka ${ }^{15}$ found - at constant superficial gas velocity - a strict proportionality between these two measured variables as predicted by Equation (14). Later experiments by $\mathrm{Mok}^{8)}$ and 
Bentahar ${ }^{3)}$ confirmed this observation in dilute -phase flow.

Equation (14), which derives from the similar profiles hypothesis, proves therefore to be in excellent agreement with all experimental data obtained in this program. Besides this, the properties of suspension pressure drop discussed above have been found to be in agreement with the predictions of Equation (13) which also derives from the similar profiles. Finally, the particle flow structure determined by Azzi corresponds exactly to the pattern predicted by Equations (10) and (11). These complementary observations have been made in two different installations using three different solids: $63 \mu \mathrm{m}$ glass beads, $60 \mu \mathrm{m}$ cracking catalyst, and coarser sand, the latter with four different particle size distributions. It can, therefore, be reasonably concluded that the characteristic flow structure of vertical gas-solids suspensions, under fully developed dilute-phase flow conditions, is that of the similar profiles regime.

Several particular properties of mass flux profiles have been deduced from Azzi's experiments. Some of these properties are in agreement with the observations deduced from the analysis of pressure drop data. Additional indications can be found in average solids velocity results.

Indeed, from the plots of $W_{s}$ vs $c$, the average solids velocity $\mathrm{V}$ at a constant superficial gas velocity $U$ can be deduced. The trend of variation of $\mathrm{V}$ is plotted in Fig. 7 as a function of $\mathrm{U}$ as per Muzyka ${ }^{15}$; the data were obtained with two different size distributions of sand. As can be seen, the relationship can be written in the form :

$\mathrm{V}=\mathrm{C}_{0} \mathrm{U}-\mathrm{C}_{1}$

where $\mathrm{C}_{0}$ and $\mathrm{C}_{1}$ are constants independent of gas velocity. The same form of functional dependence of $V$ on $U$ has been found for glass beads ${ }^{15}$, as well as for other particle size distributions of sand by $\mathrm{Mok}^{8)}$ and Bentahar ${ }^{3)}$. Moreover, Monceaux ${ }^{13)}$, found also constant coefficients $\mathrm{C}_{0}$ and $\mathrm{C}_{1}$ for cracking catalyst particles in the circulating fluidized bed installation. It should be noted, however, that in this latter case, $\mathrm{c}$ was not measured directly but deduced

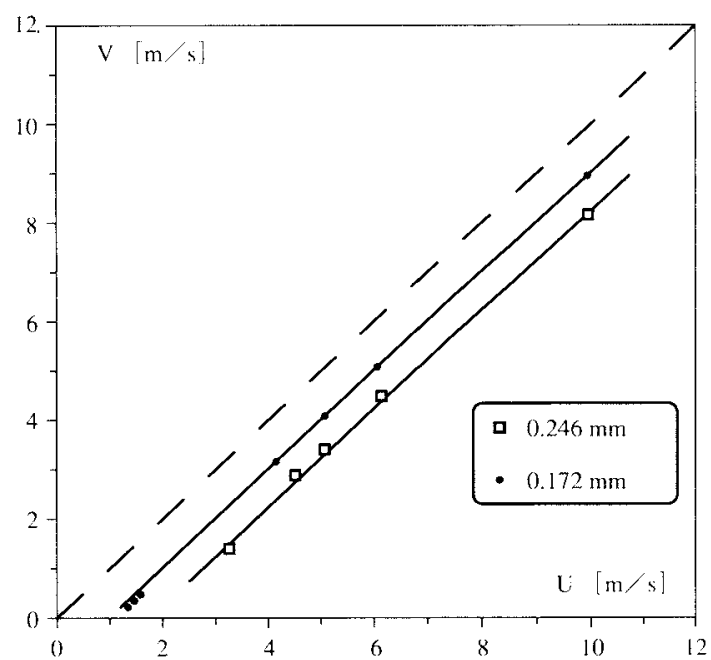

Fig. 7 Variation of average solids velocity with superficial gas velocity for sand with two different particle size distributions as per Muzyka [15]

from additional pressure drop measurements acoording to the assumptions discussed above at the end of the pressure drop section.

A constant $\mathrm{C}_{0}$ found by all these authors suggests, according to the analysis based on assumption (a) developed in $\S 2.3$, that solids concentration profiles are essentially independent of $U$, at least in the range of gas velocities investigated in these works (i.e., $2 \mathrm{~m} / \mathrm{s}$ to $10 \mathrm{~m} /$ $\mathrm{s})$. Moreover, in all experiments carried out on the pneumatic transport installation (20 $\mathrm{mm} \mathrm{ID)}$ ), $\mathrm{C}_{0}$ has been found equal to 1 as can be seen in Fig. 7. This particular value of $\mathrm{C}_{0}$ therefore suggests that according to condition (b) in $\S 2.3$, particle concentration profiles are also essentially uniform over a cross-section. For $60 \mu \mathrm{m}$ cracking catalyst particles in the $144 \mathrm{~mm}$ ID circulating fluidized bed column, Monceaux found $C_{0}=0.617$. This value is too different from 1 for the difference to be attributable to systematic errors in the indirect determination of c. An essentially uniform radial profile of particle concentration does not seem to be considered as a possibly general property in similar profiles regime. Besides, it should be noted in this connection that $\mathrm{f}(\mathrm{r}) \equiv 1$ is mathematically impossible since $\alpha_{\mathrm{s}}$ and its radial derivative should vanish at the wall ${ }^{9,10)}$. Finally, $C_{1}$ has always been found very close to the average particle terminal velocity in the $20 \mathrm{~mm}$ ID line, while the value reported by Monceaux is an order of magnitude greater than the corresponding $V_{\mathrm{t}}$. In any case, as noted in $\S 2.3$, 
additional experimental information - if not experimental evidence - is required to generalize the properties pointed out in this paragraph.

Muzyka also examined the size distribution of the particles trapped between the slide valves (i. e. the hold-up). He showed that the Sauter mean diameter of these particles remainsconstant as solids loading is increased at a constant superficial gas velocity ${ }^{15)}$. Average diameter decreases, however, with increasing U, suggesting a higher hold-up of the coarse fraction at low gas velocity. Specific behaviours of fines and coarse fractions have been particularly investigated by $\mathrm{Mok}^{8)}$, who found that the average slip velocity of each fraction was essentially equal to its terminal velocity in the similar profiles regime. Finally, Azzi did not find any significant difference in the particle size distributions of the solids mass flux samples obtained at different radial positions.

\subsection{Transition to denser flow and regime diagram}

The existence of a sharp transition from the similar profiles regime to a denser flow has been initially reported by Monceaux ${ }^{13)}$. This transition has been pointed out in a plot of the additional pressure drop measured in the 144 $\mathrm{mm}$ ID circulating fluidized bed installation against the solids rate, at constant levels of gas superficial velocity as seen in Fig. 8. For low solids loading, additional pressure drop and $\mathrm{W}_{\mathrm{s}}$

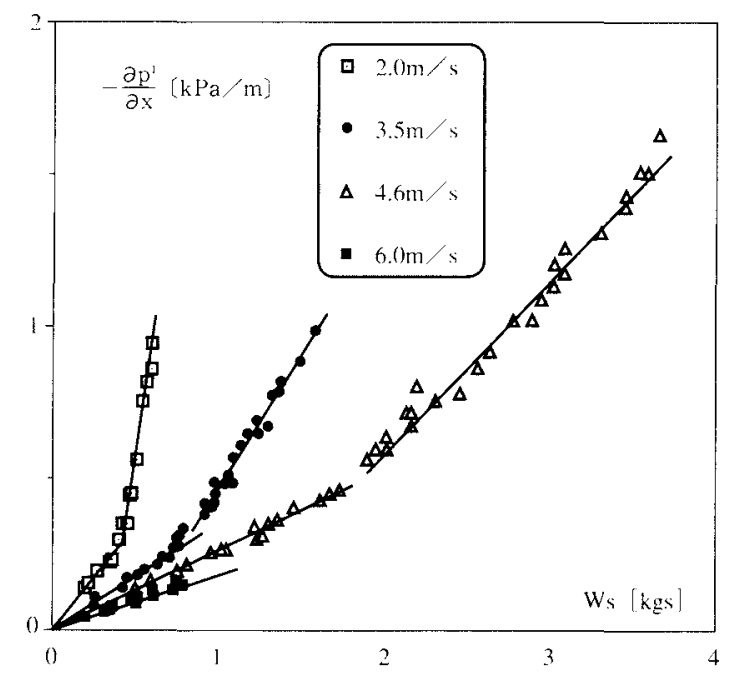

Fig. 8 Trend of variation of additional pressure drop with solids rate at different superficial gas velocities in dilute and dense-phase flow, as per Monceaux [13] . are strictly proportional as predicted in the similar profiles regime. When $W_{s}$ is further increased, the trend of variation of the pressure drop exhibits a sudden change for a critical solids rate $W_{s}{ }^{*}$. Beyond this value, the rate of change of the pressure drop with $\mathrm{W}_{\mathrm{s}}$ is higher than in the similar profiles regime.

Azzi ${ }^{1}$, determined particle mass flux profiles below and beyond this critical rate $\mathrm{W}_{\mathrm{s}}{ }^{*}$. As can be seen in Fig. 9 where a typical set of data is reported, particle mass flux profiles are no longer self-similar beyond $\mathrm{W}_{\mathrm{s}}{ }^{*}$. The change in the slopes of the straight lines in Fig. 8 corresponds, therefore, to a change in the flow structure, i.e. to a regime transition. This transition occurs for critical solids rates increasing with the gas velocity as can be clearly seen in Fig. 8 . The critical values $c^{*}$ of solids concentration can also be estimated from Fig. 8 . In the case under consideration, they range between $4 \%$ and $5 \%$, slightly depending upon gas velocity.

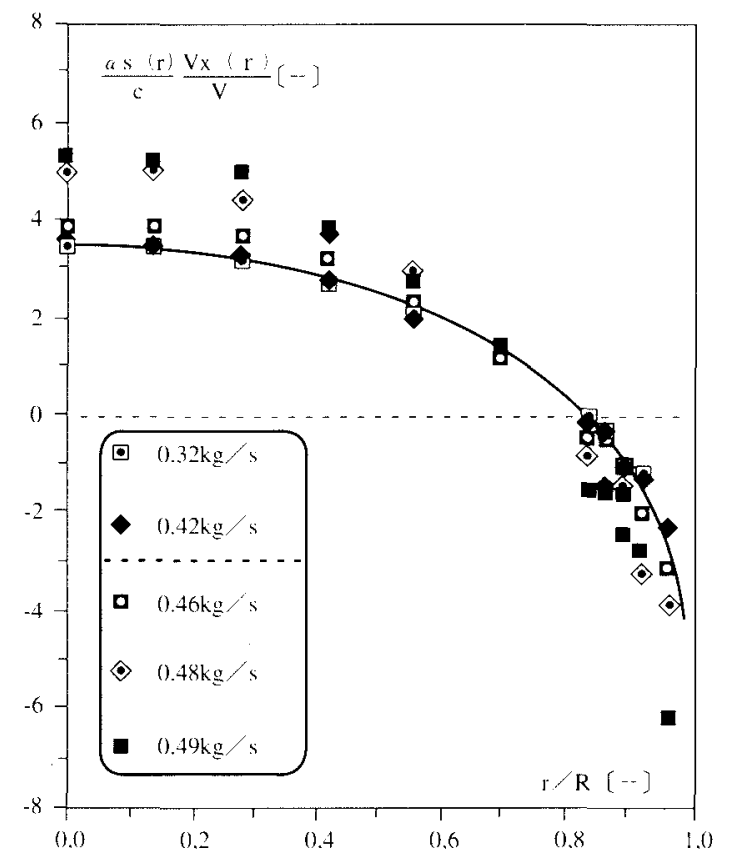

Fig. 9 Deformation of the reduced particle mass flux profiles in dense-phase flow with increasing solids loading at a superficial gas velocity of $2 \mathrm{~m} / \mathrm{s}$, as per Azzi [1]. (Solid line: similar profiles regime).

$\mathrm{Mok}^{8)}$, investigated the occurrence of a similar transition for sand particles in the $20 \mathrm{~mm}$ ID line. He found that transition can be seen either in additional pressure drop vs $\mathrm{W}_{\mathrm{s}}$, additional pressure drop vs $\mathrm{c}$, or $\mathrm{W}_{\mathrm{s}} \mathrm{vs} \mathrm{c}$ plots, in all cases 
with a sudden change in the linear relationship followed by a new linear trend of variation. These results have been confirmed by those of Bentahar ${ }^{3)}$, as can be seen in Fig. 10 where the trend of variation of overall pressure drop with $c$ at a constant superficial velocity of $4.10 \mathrm{~m} / \mathrm{s}$ is shown for $0.2 \mathrm{~mm}$ average diameter sand particles. A sudden change in the slope occurs at a critical concentration $\mathrm{c}^{*} \approx 0.01$. Beyond this point, the trend of variation remains essentially linear but the slope of the straight line is lower than its value for the similar profiles regime. Since at this level of concentration, the pressure drop of the gas alone is negligible compared to solids hold-up, the change in the slope should be attributed to the wall-particle interaction term according to Equation (6), which has a general applicability regardless of the flow structure. The experimental pressure drops in dense-phase flow are, then, consistent with the predictions of Equation (8), which derives from our wall-particle collisions model summarized in \$2.2. Indeed, Azzi found an essentially linear trend of variation with average concentration for the particle mass fluxes in the wall region beyond transition. Moreover, at low gas velocity, this trend of variation is a decrease as observed in Fig. $\mathbf{1 0}$ analyzed in conjunction with Equations (6) and (8). At high gas velocities (e.g. $10 \mathrm{~m} / \mathrm{s}$ ), Mok found a greater slope in the denser regime than in dilute phase flow. This observation is also in agreement

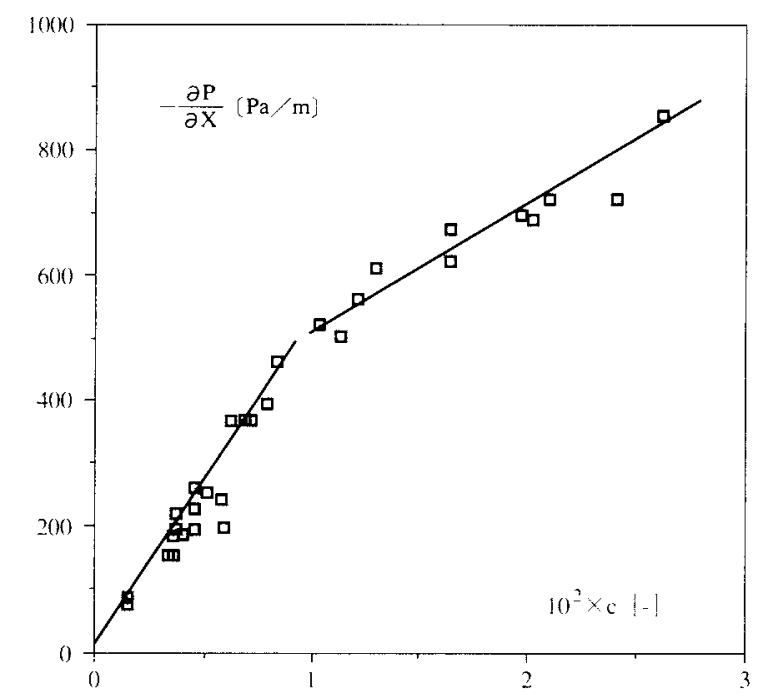

Fig. 10 Variation of suspension pressure drop with average concentration in dilute and dense-phase flow at a superficial gas velocity of $4.1 \mathrm{~m} / \mathrm{s}$, as per Bentahar [3] with the shape of particle flux profiles determined by Azzi. In other words, Equation (6) combined with Equation (8) remains valid beyond the transition to denser flow for the description of pressure drop variations.

This dense-phase flow, which occurs at a constant superficial gas velocity when the solids concentration (and/or solids rate) is increased beyond a critical value, is characterized by particle mass flux profiles which deform with increasing concentration. This deformation is at least due to that of particle velocity profiles (there is a lack of information concerning the behaviour of concentration profiles), since in Azzi's results, net particle fluxes which are positive at intermediate radial positions in the similar profiles regime become negative in denser flow conditions as can be seen in Fig. 9. As a result, average solids velocity $\mathrm{V}$ becomes a decreasing function of $\mathrm{c}^{8,13)}$. Average slip velocities either for fines or coarse particles are, moreover, higher than their terminal velocities ${ }^{8,6,7)}$. The numerical values of either solids rate or average concentration at which transition from the similar profiles regime to dense-phase flow occurs depend both on the gas -solids system, on pipe diameter, and presumably on the properties of the wall. A regime diagram such as the one shown in Fig. 8 should therefore be considered as the characteristic diagram of a gas-solids system flowing in a given installation. Besides this, Mok and $\mathrm{CO}^{-}$ workers ${ }^{8,6,7)}$, reported a second transition occurring at solids volumetric concentrations of about $5 \%$ to $6 \%$ with air suspensions of $210 \mu \mathrm{m}$ sand particles flowing in the $20 \mu \mathrm{m}$ ID pneumatic transport line.

\subsection{Wall-to-suspension heat transfer}

Wall-to-suspension heat transfer coefficients under thermally fully developed flow conditions have been measured by Muzyka in dilute-phase flow, and later by Bentahar ${ }^{3}$ for dilute and dense-phase flow. Muzyka's heat transfer results are in excellent agreement with Equation (28). Moreover, previously published heat transfer data are also consistent with this equation. These observations therefore confirm that in the similar profiles regime, the trends of variation with solids concentration, of the local temperatures of the phases are described by 
Equations (24) and (25). As a result, Equation (28) is a powerful tool for the analysis of heat transfer especially for circulating fluidized bed applications. It should be recalled, however, that for a-priori prediction purposes, coefficients $\mathrm{a}$ and $\mathrm{b}$ cannot yet be computed at the present stage of our knowledge. Muzyka ${ }^{15)}$, found that $\mathrm{a}$ and $\mathrm{b}$ depend only slightly on gas velocity in the range $4.6 \mathrm{~m} / \mathrm{s}$ to $10.2 \mathrm{~m} / \mathrm{s}$.

Equation (28) has been also confirmed by Bentahar and coworkers ${ }^{3,2)}$, as can be seen in Fig. 11 where the variations of the heat transfer coefficient are presented using a new variable $\mathrm{Y}$ defined as:

$$
\mathrm{Y}=\frac{1}{\Gamma}\left[\frac{(1+\Gamma)^{2}}{\left(\mathrm{~h}_{\mathrm{m}} / \mathrm{h}_{0}\right)}-1\right]
$$

If the heat transfer coefficient ratio is governed by Equation (28), the plot of $Y$ against $\Gamma$ would result in a straight line, the intercept of which would be equal to a and the slope to b. As can be clearly seen in Fig. 11, this prediction is confirmed by experimental results. Moreover, a sudden change in the slope of the straight line which occurs for a critical value $\Gamma^{*}$ is observed in this figure. Beyond this limit a new linear relationship is manifest. For all different superficial gas velocities investigated in her work, Bentahar found an excellent correspondence between $\Gamma^{*}$ and the critical value of the solids rate $\mathrm{W}_{\mathrm{s}}{ }^{*}$ at which transition from the similar

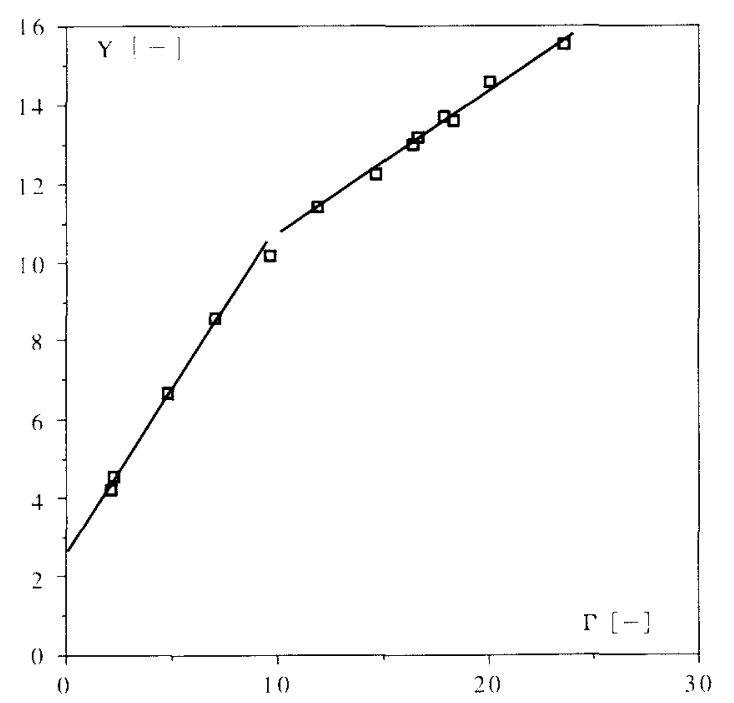

Fig. 11 Variation of wall-to-suspension heat tranrfer characteristics with solids loading in dilute and densephase flow at a superficial gas velocity of $7.7 \mathrm{~m} / \mathrm{s}$, as par Bentahar [3] profiles regime to denser flow occurs. The change in the slope of the straight line in Fig. 11 corresponds, therefore, to the effect of flow structure change on heat transfer.

Surprisingly enough, the trend of variation of $Y$ with $\Gamma$ remains linear beyond transition in all cases. In other words, Equation (28) remains valid in dense-phase flow since $a$ and $b$ assume again, beyond transition, constant numerical values which are different, however, from their respective values in the similar profiles regime. This observation suggests that in dense-phase flow at least some of the reduced concentration, velocity and temperature profiles retain their properties of independence of average concentration. At the present stage of our knowledge the analysis cannot be developed further, however, because of the lack of information concerning the functional relationships between the profiles and average concentration in densephase flow.

\section{Concluding Remarks}

In this program, the hydrodynamics and heat transfer properties of vertical fully developed flow of gas-solids suspensions have been investigated both theoretically and experimentally. The theoretical approach based on the general probabilistic multiphase flow equations proved to be a powerful tool for the analysis of suspension flows. Experiments carried out using two different installations and several different solids confirmed all theoretical predictions and provided most of the required data, as well as additional information to complete the analysis.

The correspondence between the dilute-phase flow of vertical suspensions and the theoretically defined similar profiles regime has been clearly established. Several general properties of either overall hydrodynamics or local flow structure has been pointed out as well as variable properties depending upon the characteristics of the installation. The dependence laws of temperature fields on solids concentration has been suggested from which a general equation describing the trend of variation of the wall-to -suspension heat transfer coefficient with solids loading has been derived.

A sudden transition to dense-phase flow when 
solids concentration passes beyond a specific critical value has been observed in all cases. Beyond this transition, at least some of the similarity properties of the flow structure no longer hold true. The general heat transfer equation still applies, however, with modified coefficients.

Presently, the program is still in progress, especially in connection with circulating fluidized bed reactor applications. It is primarily concerned with the flow structure of dense-phase flow and the specific conditions under which transition to dense-phase flow occurs. A general law describing mass flux profiles in both regimes is sought for the purpose of scaling-up calculations. The characteristics of the acceleration region are also investigated as well as their connections with those of the fully developed flow region. The behaviour of mixtures of particles differing by density in vertical flow is an additional concern. Finally, the characteristics of suspension flows in inclined pipes and their connections with those of vertical flow will soon be published.

\section{Nomenclature}

a : Dimensionless shape factor defined in Eq. (28) [-]

b : Dimensionless shape factor defined in Eq. (28) [-]

$B_{i j} \quad$ : Velocity cofluctuations tensor for the fluid

$\left[\mathrm{m}^{2} / \mathrm{s}^{2}\right]$

c : Volumetric solids concentration averaged over a cross-section

C : Heat capacity

$\mathrm{C}_{0} \quad$ : Constant in Eq. (30)

$\mathrm{C}_{1} \quad$ : Constant in Eq. (30) [m/s]

$[\mathrm{J} / \mathrm{kgK}]$

$\mathrm{f}(\mathrm{r}) \quad$ : Reduced solids concentration profile

$[-]$

F : Fluid-solids interaction force

$\left[\mathrm{N} / \mathrm{m}^{3}\right]$

g : Acceleration of gravity $\left[\mathrm{m} / \mathrm{s}^{2}\right]$

$\mathrm{h} \quad$ : Heat transfer coefficient $\left[\mathrm{W} / \mathrm{m}^{2} \mathrm{~K}\right]$

$\mathrm{K} \quad$ : Constant defined in Eq.(8) [m/s]

$\mathrm{O}\left(\mathrm{c}^{2}\right)$ : Second order terms in a series development

$\mathrm{p} \quad:$ Pressure $\quad[\mathrm{Pa}]$

$Q_{\mathrm{fs}} \quad$ : Heat rate transferred from the fluid to the solids

$\mathrm{r} \quad$ : Radial coordinate

$\left[\mathrm{W} / \mathrm{m}^{3}\right]$

$\mathrm{R} \quad$ : Pipe radius [m]

$\begin{array}{llr}\mathrm{s}_{\mathrm{ij}} & \text { : Intergranular stress tensor } & {[\mathrm{Pa}]} \\ \mathrm{t} & \text { : Time } & {[\mathrm{s}]} \\ \mathrm{T} & \text { : Temperature } & {[\mathrm{K}]} \\ \mathrm{Ui} & \text { : Gas velocity components } & {[\mathrm{m} / \mathrm{s}]} \\ \mathrm{U} & \text { : Superficial gas velocity } & {[\mathrm{m} / \mathrm{s}]} \\ \mathrm{V}_{1} & \text { : Solids velocity components } & {[\mathrm{m} / \mathrm{s}]} \\ \mathrm{V}_{\mathrm{t}} & \text { : Terminal velocity of the solids } \\ & & {[\mathrm{m} / \mathrm{s}]} \\ \mathrm{V} & \text { : Average solids velocity } & {[\mathrm{m} / \mathrm{s}]} \\ \mathrm{W} & \text { : Mass flowrate } & {[\mathrm{kg} / \mathrm{s}]} \\ \mathrm{X} & \text { : Axial coordinate } & {[\mathrm{m}]} \\ \mathrm{X}_{1}, \mathrm{x}_{\mathrm{j}} & \text { : Cartesian coordinates (tensor nota- } \\ & \text { tion) } & {[\mathrm{m}]} \\ \mathrm{Y} & \text { : Heat transfer function defined in Eq. }\end{array}$

(31)

$[-]$

\section{Greek symbols}

$\alpha \quad$ : Phase presence probability $\quad[-]$

$\beta_{1 j} \quad$ : Velocity cofluctuations tensor for the solids

$\Gamma \quad$ : Ratio defined in Eq. (27) $\quad[-]$

$\varepsilon_{1} \quad:$ Velocity-temperature cofluctuations vector $\quad[\mathrm{mK} / \mathrm{s}]$

$\varphi \quad$ : Unit heat flux $\quad\left[\mathrm{W} / \mathrm{m}^{2}\right]$

$\lambda \quad:$ Heat conductivity $\quad[\mathrm{W} / \mathrm{mK}]$

$\theta \quad$ : Radial temperature profile $[\mathrm{K}]$

$\rho \quad:$ Density $\quad\left[\mathrm{kg} / \mathrm{m}^{3}\right]$

$\sigma_{i j} \quad:$ Stress tensor acting within the solids phase $\quad[\mathrm{Pa}]$

$\tau_{i j} \quad:$ Viscous stress tensor $\quad[\mathrm{Pa}]$

\section{Subscripts and superscripts}

$\begin{array}{ll}\mathrm{f} & : \text { Fluid phase } \\ \mathrm{i}, \mathrm{j} & : \text { Tensor notation } \\ \mathrm{I} & : \text { Interface } \\ \mathrm{m} & : \text { Mixture (Gas + solids) } \\ \mathrm{M} & : \text { Mixed mean (temperature) } \\ \mathrm{p} & : \text { Phase p } \\ \mathrm{r} & : \text { Radial projection } \\ \mathrm{rel} & : \text { Relative or slip (velocity) } \\ \mathrm{s} & : \text { Solids phase } \\ \mathrm{vw} & : \text { In the vicinity of the wall } \\ \mathrm{w} & : \text { At the wall } \\ 0 & : \text { Zeroth order terms in series develop- } \\ & \text { ments (Reference flow) } \\ 1 & : \text { First order terms in series develop- } \\ & \text { ments } \\ * & : \text { Critical conditions (transition) }\end{array}$

\section{References}

1) Azzi, M.: Etude des profils de flux de par- 
ticules dans l'écoulement vertical établi d' une suspension gaz-solides, Thèse de Doctorat, Université de Technologie de Compiègne, Compiègne (1986)

2) Bentahar, F., Molodtsof, Y., Large, J.F., Alia, K.: Heat Transfer to Vertically Flowing Dilute and Dense-Phase Gas-Solids Suspensions, A.I.Ch.E. Symp. Series No 276, 86 (1990), 10-15

3) Bentahar, F.: Ecoulement vertical d'une suspension dense: Hydrodynamique et transfert thermique suspension-paroi, Thèse de Doctorat d'Etat, Université des Sciences et de la Technologie d'Alger / U.T.C., Algiers (1992)

4) Hariu, O.H., Molstad, M.C.: Pressure Drop in Vertical Transport of Solids by Gases, Ind. Eng. Chem., 41 (1949) 6, 1148-1160

5 ) Maeda, M., Saigusa, T., Ikai, S.: Study of Heat Transfer to Gas-Solids Suspension Part 1: Influence of Free Turbulence on Heat Transfer, Bull. J.S.M.E., 19 (1976) 137, 1317-1325

6) Mok, S.L.K., Molodtsof, Y., Large, J.F., Bergougnou, M.A.: Hydrodynamic Characteristics of Dilute and Dense-Phase Flows in Vertical Pneumatic Transport, Proc. 37 th Canadian Conf. Chem. Eng., Montréal, (1987)

7) Mok, S.L.K., Molodtsof, Y., Large, J.F., Bergougnou, M.A.: Characterization of Dilute and Dense-Phase Vertical Upflow Gas-Solid Transport Based on Average Concentration and Velocity Data, Canadian J. Chem. Eng., 67 (1989), 10-16

8 ) Mok, S.L.K.: The Study of Hydrodynamic Characteristics of Vertical Upflow GasSolids Suspension in Dilute and DensePhase Regimes, $\mathrm{Ph}$. D. Thesis, University of Western Ontario, London, Canada (1991)

9) Molodtsof, Y.: Equations Générales Probabilistes des Ecoulements Polyphasiques et applications aux mélanges gazsolides, Thèse de Doctorat d'Etat, Université de Technologie de Compiègne, Compiègne (1985)

10) Molodtsof, Y., Muzyka, D.W.: General Probabilistic Multiphase Equations for Analysing Gas-Solids Mixtures, Int. J. Eng. Fluid Mech., 2 (1989) 1, 1-24

11) Molodtsof, Y., Muzyka, D.W.: A Similar Profile Regime in the Vertical Fully Devel- oped Flow of Gas-Solids Suspensions, Int. J. Multiphase Flow, 17 (1991) 5, 573-583

12) Molodtsof, Y., Muzyka, D.W.: Wall-toSuspension Heat Transfer in the Similar Profiles Regime, Int. J. Heat Mass Transfer, 35 (1992) 10, 2665-2673

13) Monceaux, L.: Etude des régimes d'écoulement dans un lit circulant, Thèse de Docteur-Ingénieur, Université de Technologie de Compiègne / E.N.S.P.M., Compiègne (1985)

14) Muzyka, D.W., Molodtsof, Y., Large, J.F., Bergougnou, M.A.: Application of Probabilistic Multiphase Flow Equations to Dilute-Phase Pneumatic Transport, Proc. 33 rd Canadian Conf. Chem. Eng., Toronto (1983)

15) Muzyka, D.W.: The Use of Probabilistic Multiphase Flow Equations in the Study of the Hydrodynamics and Heat Transfer in Gas-Solids Suspensions, Ph. D. Thesis, University of Western Ontario, London, Canada (1985) 